OPEN ACCESS

Edited by:

Kalliopi Dodou,

University of Sunderland, UK

Reviewed by:

Simon Keely,

University of Newcastle, Australia

Ennio Tasciotti

Houston Methodist Research Institute,

USA

*Correspondence:

Amanda E. Brooks

amanda.e.brooks@ndsu.edu

Specialty section:

This article was submitted to Medicinal and Pharmaceutical

Chemistry,

a section of the journal

Frontiers in Chemistry

Received: 03 September 2015 Accepted: 09 November 2015 Published: 26 November 2015

Citation:

Brooks AE (2015) The Potential of Silk and Silk-Like Proteins as Natural Mucoadhesive Biopolymers for Controlled Drug Delivery.

Front. Chem. 3:65.

doi: 10.3389/fchem.2015.00065

\section{The Potential of Silk and Silk-Like Proteins as Natural Mucoadhesive Biopolymers for Controlled Drug Delivery}

\author{
Amanda E. Brooks * \\ Department of Pharmaceutical Sciences, North Dakota State University, Fargo, ND, USA
}

Drug delivery across mucus membranes is a particularly effective route of administration due to the large surface area. However, the unique environment present at the mucosa necessitates altered drug formulations designed to (1) deliver sensitive biologic molecules, (2) promote intimate contact between the mucosa and the drug, and (3) prolong the drug's local residence time. Thus, the pharmaceutical industry has an interest in drug delivery systems formulated around the use of mucoadhesive polymers. Mucoadhesive polymers, both synthetic and biological, have a history of use in local drug delivery. Prominently featured in the literature are chitosan, alginate, and cellulose derivatives. More recently, silk and silk-like derivatives have been explored for their potential as mucoadhesive polymers. Both silkworms and spiders produce sticky silk-like glue substances, sericin and aggregate silk respectively, that may prove an effective, natural matrix for drug delivery to the mucosa. This mini review will explore the potential of silk and silk-like derivatives as a biocompatible mucoadhesive polymer matrix for local controlled drug delivery.

Keywords: silk, sericin, mucoadhesive, drug delivery, biopolymers, aggregate silk

\section{INTRODUCTION}

The rising need for tissue compatible adhesives is expected to generate a $\$ 38$ billion global market by 2017 (Bré et al., 2013). A subset of this market is being driven by the pharmaceutical industry. Localized transmucosal drug delivery constitutes a large and growing share of the market, with an estimated value of $\$ 6.7$ million (U.S.) in 2006 (Andrews et al., 2009) and \$2.91 billion (global) in 2013 (Micromarket Monitor ${ }^{1}$ ). Based on a compound annual growth rate of $6.8 \%$, global transmucosal drug delivery is projected to be a $\$ 4.05$ billion market segment by 2018 (Micromarket Monitor). This growing market is demanding a new and diverse set of polymers. Local drug delivery and retention, particularly at a biological surface, can often be accomplished through the use of bioadhesive polymers. Mucoadhesives, a class of bioadhesives, serve a critical niche in transmucosal drug delivery as the unique environment at the mucosal surface requires altered drug formulations. The mucosal membrane is typically composed of a specialized epithelial cell layer covered with mucin to facilitate gas and nutrient exchange (Yu et al., 2014). The physiological function of the

\footnotetext{
${ }^{1}$ Micromarket Monitor Global Transmucosal Drug Delivery Market Research Report. Available online at: http:// www.micromarketmonitor.com/market-report/transmucosal-drug-delivery-reports-5655777892.html [Accessed August 24, 2015].
} 
mucosal membrane can be exploited to facilitate pharmaceutical dosing. Mucoadhesive polymers, including both synthetic and natural polymers, have generated intense and growing interest in the past decades (Grabovac et al., 2005; Khutoryanskiy, 2011; Mythri et al., 2011). In addition to a host of synthetic polymers, prominently featured in the literature are chitosan, alginate and cellulose derivatives. Recently, several silk and silklike derivatives have been evaluated for their adhesive properties. This mini review will describe the mucoadhesive properties of silk and silk-like derivatives that justify them being explored as biocompatible mucoadhesive polymer matrices for localized, controlled transmucosal drug delivery.

\section{MECHANISMS OF MUCOADHESION}

A variety of mucous membranes exist throughout the human body to lubricate and protect the interface between the internal and external environments of the body. Several good reviews describing the characterization and central role of mucin in mucous membranes are available and will not be further reviewed here except to say that the mucin component of the mucous membrane forms a glyocoprotein gel-like network that proves critical to mucoadhesion (Marriott and Gregory, 1990; Smart, 2005; Andrews et al., 2009; Khutoryanskiy, 2011; Yu et al., 2014). Although the precise mucin organization and identification may vary based on mucosal location (i.e., nose, eye mouth, stomach, intestine, vagina), there are six main theories of mucoadhesion with many principles of mucoadhesion remaining consistent: (1) the wetting theory, which describes mucoadhesion as a product of the intermolecular interactions and interfacial tension between the mucosal surface and the adhesive; (2) the mechanical interlocking theory, which proposes that mucoadhesion results from the mechanical interlocking of the adhesive and features of the substrate surface; (3) the electronic transfer theory, where electrons transfer between the adhesive and the surface creating critical electrostatic forces; (4) the diffusion interpenetration theory, which describes mucoadhesion as a result of the interpenetration and entanglement of polymer and mucin chains dominated by electrostatic attractions; (5) the adsorption theory, which describes mucoadhesion as being an accumulation of primary (i.e., ionic and covalent) and secondary (i.e., van der Waals forces, hydrogen bonding, electrostatic attraction, and hydrogen bonds) bond formation; and (6) the fracture theory, which does not offer a chemical or molecular explanation of mucoadhesion but simply relates the adhesive strength to that necessary to separate the adhesive and mucous membrane (Smart, 2005; Andrews et al., 2009; Shaikh et al., 2011; Tangri, 2011; Yu et al., 2014). Importantly, the underlying mechanism of mucoadhesion is not completely clear and may result from a combination of these theories (Smart, 2005); furthermore, the adhesive strength and consequently the utility of different mucoadesive polymers is not the same for all mucous membranes (Accili et al., 2004). Notably, certain mucoadhesive polymers, including natural biopolymers, may have altered degradation in the GI tract due to the presence of the microbiome or other pathological conditions [i.e., inflammation, ulcerative colitis, etc. (Seves et al., 1998; Hua et al., 2015)]. Thus, awareness of the theories is essential to the design of mucoadhesive polymers for drug delivery systems.

\section{MUCOADHESIVE POLYMERS}

Regardless of the specific mucoadhesive mechanism, there are some promising candidate polymers in development for drug delivery. General characteristics and classifications of mucoadhesive polymers are presented in this review with examples to illustrate their utility as drug delivery systems opposed to an in depth discussion of all possible polymers.

\section{Characteristics of Polymers}

The appropriate polymer choice for local mucoadhesive drug delivery relies on a combination of (1) the polymer's chemical reactivity and stereochemistry, (2) its molecular weight and concentration, (3) its side group flexibility and steric hindrance, and (4) its ability to swell and adhere to tissues under moist or high humidity conditions (Andrews et al., 2009; Shaikh et al., 2011; Tangri, 2011). Commonly used mucoadhesive polymers generally have polar groups (hydroxyl, carboxyl, amide, sulfate) available for interaction with mucin as well as molecular weights that fall in the range of $10^{4} \mathrm{Da}$ to $4 \times 10^{6} \mathrm{Da}$ to facilitate the interaction (Smart, 2005; Andrews et al., 2009). Polymers that fall on the upper end of this range may not have sufficient flexibility to swell and adhere while those that are below this range will only form weak adhesives and readily dissipate. First generation or non-specific mucoadhesive polymers, whether synthetic or natural, are generally hydrophilic with functional groups that allow for hydrogen bonding and electrostatic interactions. Alternatively, second generation mucoadhesive polymers such as lectins (Clark et al., 2000; Lehr, 2000; Haas and Lehr, 2002; Kim et al., 2015), invasins, thiolated polymers (Bernkop-Schnürch et al., 2004b; Cevher et al., 2008a,b), antibodies, and other proteins (Woodley, 2001; Bravo-Osuna et al., 2007) are developed to facilitate specific interactions and overcome biological barriers (Carvalho et al., 2010). A review of synthetic mucoadhesive polymers will not be presented in this mini-review, but instead the reader is referred to several reviews on the subject (Grabovac et al., 2005; Ludwig, 2005; Salamat-Miller et al., 2005; Valenta, 2005; Catron et al., 2006; Andrews et al., 2009; Carvalho et al., 2010; Mythri et al., 2011; Yu et al., 2014).

\section{Natural Polymers}

In this synthetic landscape, a host of natural polymers have been explored as mucoadhesive drug carriers (Ceulemans et al., 2002; George and Abraham, 2006; Wittaya-areekul et al., 2006; Kalu et al., 2007) and are often preferred for biomedical applications due to their reputation for "green" processing, renewability, and biocompatibility (Ngwuluka et al., 2014). Notably, biocompatibility, specifically immunocompatibility, may be a product of purity, which could be challenging for natural sources (Lehr, 2000). Many naturally mucoadhesive polymers are very large polymeric proteins and have repetitive patterned structural elements organized in a structural hierarchy, particularly in the silks (Table 1). The mechanism of mucoadhesion for many of these natural polymers seems 
TABLE 1 | Comparison of the repetitive primary structural elements of natural adhesive polymers.

\begin{tabular}{|c|c|c|c|c|}
\hline Natural polymer & $\begin{array}{l}\text { Amino acid motif/Chemical } \\
\text { structure }\end{array}$ & Ecological purpose & $\begin{array}{l}\text { Adhesion } \\
\text { strength }\end{array}$ & References \\
\hline Sericin & $\begin{array}{l}\text { (SSTGSSSNTDSNSNSVGSS } \\
\text { TSGGSSTYGYSSNSRDGSV)n }\end{array}$ & $\begin{array}{l}\text { Sticky outside } \\
\text { coating }\end{array}$ & $4.1 \pm 2 \mathrm{~N}$ & Ahn et al., 2001 \\
\hline Silkworm firboin & GAGAGS, GX $X_{n}$, where $X=A, Y, V$ & Core of silk fiber & $\begin{array}{l}54 \mathrm{mN} \text { or } 146.6 \\
\mathrm{mN} / \mathrm{cm}^{2}\end{array}$ & $\begin{array}{l}\text { Jiang et al., 2006; } \\
\text { Kundu et al., 2008a }\end{array}$ \\
\hline Aggregate silk & $\begin{array}{l}\text { Gly-rich (64-mer), XPGXG (36-mer,) } \\
\text { GGX/NXNXN (33-mer) }\end{array}$ & Aqueous glue for web & $0.1-0.4 \mathrm{mN}$ & $\begin{array}{l}\text { Sahni et al., 2011; } \\
\text { Vasanthavada et al., } \\
\text { 2012; Opell et al., } 2013\end{array}$ \\
\hline Piriform silk & QQSSVA, PXPXP & Attachment cement & $39.8 \pm 8.9 \mathrm{mN}$ & $\begin{array}{l}\text { Perry et al., 2010; } \\
\text { Grawe et al., 2014; } \\
\text { Wolff et al., } 2015\end{array}$ \\
\hline Caddisfly silk & $\begin{array}{l}\text { O-phospho-ser cluster }(\mathrm{SX})_{\mathrm{n}} \text { where } \mathrm{X}= \\
\mathrm{V}, \mathrm{L}, \mathrm{I}, \mathrm{R} \text {; and } n \text { is } 2-6\end{array}$ & $\begin{array}{l}\text { Underwater cement } \\
\text { for protective case }\end{array}$ & $\begin{array}{l}32.7 \pm 6.6 \mathrm{MPa} \\
\text { (stress at fracture) }\end{array}$ & $\begin{array}{l}\text { Ohkawa et al., 2013; } \\
\text { Lane et al., } 2015\end{array}$ \\
\hline Chitosan & $\underbrace{\mathrm{OH}}_{\mathrm{NH}_{2}}$ & Shellfish & $\begin{array}{l}32.4 \pm 14.5 \mathrm{mN} \\
3.9-6.7 \mathrm{mN} / \mathrm{cm}^{2}\end{array}$ & $\begin{array}{l}\text { Bernkop-Schnürch and } \\
\text { Freudl, 1999; Lehr } \\
\text { et al., } 1992\end{array}$ \\
\hline
\end{tabular}

Note that the values for adhesion strength cannot be compared due to different techniques used to gather the data.

to begin with physical entanglement and ultimately relies on the use of secondary, non-covalent bonds, similar to other first generation mucoadhesive polymers. However, common chemical modifications (e.g., DOPA, etc.) are also found in natural mucoadhesive polymers and offer important insight in to mucoadhesion (Lee et al., 2002; Bré et al., 2013). These characteristics provide a foundation that allows for tunable drug release and permeability based on secondary structural elements, a distinct advantage over many synthetic alternatives.

\section{Chitosan}

Chitosan is perhaps the most studied natural mucoadhesive polymer and has been extensively considered for drug delivery due to its mucoadhesive and stimuli responsive nature. Interestingly, without modification, chitosan, a derivative of shellfish, has an adhesive force that exceeds both carboxymethylcellulose and polycarbophil, two of the most common synthetic mucoadhesives used in drug delivery (Bravo-Osuna et al., 2007; Ngwuluka et al., 2014). This versatile natural polymer exemplifies the mucoadhesion of the amino functionality of a cationic polymer to the sialic groups of mucin through electrostatic interactions at physiological $\mathrm{pH}$ (Carvalho et al., 2010; Kim et al., 2015) and has been used to deliver many drugs [e.g., metronidazole vaginally (Valenta, 2005), AZT nasally (Barbi et al., 2015), and pilocarpine ocularly (Li and $\mathrm{Xu}, 2002)$, etc.]. Unfortunately, despite its promise, there are no FDA approved chitosan drug delivery systems currently (Kean and Thanou, 2010; Rodrigues et al., 2012; Thakur and Thakur, 2015). Like PEG, chitosan can be readily functionalized to improve its mucoadhesion (Andrews et al., 2009). During the delivery of rhodamine or calcitonin, thiolation of chitosan has been shown to (1) increase its mucoadhesive strength by allowing disulfide bridges with mucous glycoprotein cysteine residues, (2) promote mucous permeation, and (3) prevent protease activity by sequestering zinc and magnesium, important cofactors for protease activity (Bernkop-Schnürch et al., 2004a,b; Grabovac et al., 2005; Bravo-Osuna et al., 2007; Cevher et al., 2008a). Importantly, thiolation may not be appropriate for all mucoadhesive drug delivery systems due to formation of stable, yet short lived, disulfide bonds with mucin, increasing mucoadhesion up to 130-fold when FITC-dextran was delivered (Bernkop-Schnürch et al., 2004b; Shaikh et al., 2011; Kim et al., 2015). Chitosan has also been complexed with catechol, a side chain of DOPA, to increase in vivo retention and release of 
orally-delivered insulin for up to $10 \mathrm{~h}$, as opposed to less than $3 \mathrm{~h}$ for chitosan alone (Kim et al., 2015). Alternatively, when chitosan was mixed with a catechol-containing compound, hydrocaffeic acid, and tested in a rabbit intestine, swelling could be decreased with a corresponding increase in mucoadhesion and release of hydrocaffeic acid (Xu et al., 2012). The ability to modify chitosan and create the specificity of binding, characteristic of a second generation mucoadhesive, will provide significant advances in the ability to use chitosan for transmucosal drug delivery, particularly for membranes with high turn-over.

\section{Viscoelastic spider silk glues}

Unlike chitosan, viscoelastic spider silk glues, while long recognized for their adhesive properties, have yet to find a niche in mucoadhesive drug delivery. Although previous research efforts to use spider silk as a drug carrier (Hofmann et al., 2006; Lammel et al., 2010; Gomes et al., 2012) have focused on the mechanically robust solid major ampullate and flagelliform fibers, aggregate silk glue, and even the piriform cement, are promising mucoadhesive polymer alternatives (Opell and Hendricks, 2009; Sahni et al., 2010). Recently, the primary sequences of both piriform (Perry et al., 2010) and aggregate silk proteins have been determined and the presence of chemical binders such as DOPA to provide adhesive strength is notably lacking (Sahni et al., 2011; Jones et al., 2015). Nevertheless, according to the Dahlquist criteria for adhesives, materials with robust adhesion should have a Young's modulus lower than $100 \mathrm{kPa}$; atomic force microscopy has measured the average Young's modulus of aggregate silk glue to be $70 \pm 47 \mathrm{kPa}$ (Torres et al., 2014). Thus, the fundamental basis of this robust adhesion may lie in the structural hierarchy, a proteinaceous block co-polymer composed of two proteins, ASG1 and ASG2, with a repetitive amino acid motif architecture (Choresh et al., 2009; Vasanthavada et al., 2012; Wolff et al., 2015). Additionally, similar to other natural and synthetic mucoadhesive polymers, ASG1 has a high percentage of charged amino acids, while ASG2 has a motif structure similar to elastin providing the mobility necessary for swelling and interaction with mucin (Choresh et al., 2009; Sahni et al., 2014). This balance of adhesion and elasticity arising from a composite material is a common theme in natural bioadhesives (Lee, 2010) and likely leads to effective dissipation of mechanical forces and mucoadhesion. In fact, the structural hierarchy and heteromeric composition of these silk glues produces an anisotropic material that may limit crack propagation, effectively increasing adhesion strength (Wolff et al., 2015). In addition to the protein composition and organization, aggregate silk has a viscous glycoprotein core surrounded by an aqueous solution of salts (Sahni et al., 2014). Importantly, studies have shown that the glycoprotein component of aggregate silk glue shares several characteristics with mammalian mucin molecules (Choresh et al., 2009). Currently, aggregate silk has not been specifically assessed for mucoadhesion; however, its ability to adhere in a high humidity environment makes it a potentially useful polymer. In fact, as humidity increases, the adhesive strength of aggregate silk glue also increases (Opell et al., 2013; Amarpuri et al., 2015). Although not specifically studied for aggregate silk, a $\mathrm{pH}$ gradient may also solidify aggregate silk providing more strength and stability similar to major ampullate silk (Breslauer et al., 2009; Andersson et al., 2013). Further contributing to its potential as a mucoadhesive polymer, the charge of ASG1 has a strong similarity to chitin-binding proteins and should react similarly to changes in $\mathrm{pH}$ (Sahni et al., 2014). The composition and structural organization of aggregate silk in addition to its environmentally dependent behavior could prove a critical clue in the use of a silk-based mimetic glue as a mucoadhesive polymer, specifically for drug delivery.

In addition to a viscous aggregate silk glue, spiders also produce piriform silk, a cemented attachment disk, as a solid fiber and fibrous cement composite (Wolff et al., 2015). The cement component, which has a high content of polar and charged amino acids similar to other mucoadhesives (Blasingame et al., 2009; Geurts et al., 2010; Grawe et al., 2014), acts as a viscoelastic fluid capable of filling surface microarchitecture to provide a high contact area that heavily relies on hydrogen bonding for it adhesive strength (Wolff et al., 2015). The anisotropic organization may again provide a level of robust adhesion not achieved with other non-silk bioadhesives.

\section{Silkworm-derived adhesives}

In contrast to spiders, silkworms can be farmed, providing a level of accessibility for research and commercialization not currently possible with spider silk adhesives, which rely on recombinant development and is still in its infancy. Silkworms produce a single type fiber with a two chain composite fibroin core and a sericin coating (Zhang, 2002; Yucel et al., 2010). The core fibroin is capable of binding to glycoproteins and proteoglycans (Jiang et al., 2006; Dong et al., 2015). Recently, silkworm fibroin was solubilized and processed as a $\mathrm{pH}$-sensitive hydrogel via electrogelation (e-gel) (no drug was released), demonstrating adhesion likely due to secondary bond interactions (e.g., hydrogen bonds and van der Waals interactions). The authors noted that the promising adhesive strength of these e-gels will be assessed for their mucoadhesive abilities in future studies (Yucel et al., 2010). Other efforts to create new "green" silk-based mucoadhesives have complexed silk fibroin with other synthetic polymers. Recently, solubilized silkworm fibroin was combined with a chemically active polyethylene glycol to provide strong adhesive properties (Serban et al., 2011). At a 20\% w/v of silk, the adhesive strength of the composite was greater than that of the commercially available CoSeal tissue sealant. Alternatively, silk fibroin was combined with hydroxy propyl methyl cellulose (HPMC) and PEG to create a robust mucoadhesive film for transmucosal drug delivery, although the study did not actually provide any specific drug release kinetics (Kundu et al., 2008a).

The sericin fraction of silkworm silk, which constitutes 25$30 \%$ of the silk protein and is routinely discarded during silkworm cocoon processing, can also be blended with a variety of different polymers including sodium alginate (De, 2003; Khandai et al., 2010), polyvinylalchol, polyacrylic acid, and acrylamide to delay and control the release of a pharmaceutical (Ahn et al., 2001; Zhang, 2002; Khandai et al., 2010). Importantly, sericin separated from the fibroin core is inherently adhesive as well (Teramoto and Miyazawa, 2005; Khandai et al., 2010); however, conjugation of sericin with other polymers is reported to stabilize 
the structure and mitigate residual immunogenicity (Kundu et al., 2008b).

\section{Caddisfly silk}

Analogous to the aggregate silk secreted by orb-weaving spiders, caddisflies also secrete an adhesive silk-like protein with impressive strength (Stewart and Wang, 2010; Lane et al., 2015). However, unlike aggregate silk, sericin, chitosan, and the DOPA residue similar to that found in the underwater adhesive of muscles, evidence suggests that the adhesive force of caddisfly silk results from the post translational phosphorylation of serine, L-O-phospho-serine $\left(\operatorname{Ser}\left(\mathrm{PO}_{3} \mathrm{H}_{2}\right)\right.$ ) (Ashton et al., 2013). It has been suggested that the caddisfly uses $\operatorname{Ser}\left(\mathrm{PO}_{3} \mathrm{H}_{2}\right)$ providing for very strong adhesion likely due to a combination of covalent-crosslinking and electrostatic interactions (Stewart et al., 2011; Ohkawa et al., 2013); however, the precise mechanism is not clear (Wang et al., 2009). The viscous silk-like substance and adhesive acts as an underwater cement to adhere small stones and pebbles to one another to create a protective case; however, the requirements for adhesion between two hard surfaces may prove to be very different from that required for mucoadhesion. Nevertheless, the underwater performance of the material may prove a compelling reason to consider its mucoadhesive properties.

\section{MUCOADHESION IN DRUG DELIVERY}

Since its inception in the 1980s, mucoadhesion has become an increasingly popular alternative drug delivery platform due to its multiple advantages and the advent of multifunctional polymers. The mechanism of release from the different mucoadhesive polymers is often dependent on the site, the $\mathrm{pH}$, and the polymer's swelling characteristics, but overall release is dominated by diffusion and swelling with the primary advantage of the system derived from increased residence time (Yadav et al., 2010; Fini et al., 2011; Mythri et al., 2011).

\section{Advantages}

\section{Residence Time}

Arguably, the primary advantage of mucoadhesive mediated drug delivery is the increased local residence time at the desired site of action due to improved contact (Woodley, 2001; Carvalho et al., 2010; Mythri et al., 2011; Yu et al., 2014). One of the clearest demonstrations of the effect is in ocular (Dong et al., 2015) applications where silk fibroin has been used to coat liposomes for ocular ibuprofen drug delivery to increase the residence time in the precorneal area of the eye. Similar results can also be obtained by replacing silk fibroin with chitosan (Kim et al., 2015), hyaluronan, or cellulose derivatives (Dong et al., 2015). This feature has recently been demonstrated in preclinical studies of ophthalmic drug inserts to treat external ophthalmic diseases in a canine model, which reduced dosing applications to a single treatment (Baeyens et al., 2002). Examples of enhanced drug delivery via mucoadhesion, although not necessarily with silk, can also be found in oral (e.g., FDAapproved Striant testosterone bucal system), nasal (e.g., insulin), gastrointestinal (e.g., many antibiotics; Batchelor, 2005), and vaginal applications (e.g., progesterone; Donnelly and Woolfson, 2015). Additionally, mucoadhesive gels and gel-like particles with their associated rheological properties decrease the mucous clearance and increase the contact time, effectively reducing dosing frequency and increasing patient compliance (Tangri, 2011; Yu et al., 2014).

\section{Enhanced Safety and Efficacy}

Mucoadhesive drug delivery often provides enhanced safety and efficacy rooted in the (1) ability to target the mucosa (Woodley, 2001), (2) improved bioavailability of the drug (Woodley, 2001; Mythri et al., 2011; Shaikh et al., 2011; Tangri, 2011), (3) abundant blood flow associated with mucosal surfaces, which will quicken the onset of action (Tangri, 2011), (4) protection of peptide drugs from protease degradation (Bernkop-Schnürch et al., 2004b), and (5) circumvention of first-pass hepatic metabolism (Andrews et al., 2009). Thiolation has also been reported to enhance penetration of the drug (Bernkop-Schnürch et al., 2004b). The nasal administration of insulin as a bioadhesive powder provides an excellent example of the power of mucoadhesive drug delivery (Nagai et al., 1984).

\section{Barriers}

Unfortunately, several barriers hamper the rapid clinical translation of mucoadhesive drug delivery. Barriers to the implementation of successful mucoadhesive drug delivery systems can be divided into either technical limitations of characterization or more inherent biological obstacles.

\section{Mechanical Assessment}

Evaluation of new mucoadhesive polymers requires both in vitro and in vivo testing to determine adhesive strength, and yet, as with most in vivo/in vitro correlations, there is a disconnect in the methodologies (Khutoryanskiy, 2011). Although there are three main testing methods recognized-tensile tests, shear strength, and peel strength with rheology often being included depending on the proposed application, uniform methodologies have not been established (Andrews et al., 2009; DavidovichPinhas and Bianco-Peled, 2010; Khutoryanskiy, 2011; Shaikh et al., 2011; Tangri, 2011; Woertz et al., 2013; Yu et al., 2014). Khutoryanskiy provides a nice review of the various testing methods with a discussion of their advantages and disadvantages (Khutoryanskiy, 2011). Lack of uniform testing tools not only hampers comparison of mucoadhesive polymers and drug delivery systems but also proves a critical logistical barrier to regulatory approval. Additionally, the advent of nanoscale pharmaceutical therapies has left a significant void in the methodologies to assess nanoscale mucoadhesion as opposed to macroscale bulk adhesion (Das Neves et al., 2011).

\section{Biological Factors}

In addition to poor methodologies for assessment, many in vitro assessments are inaccurate in vivo due to biological factors. Several biological factors can affect the feasibility and effectiveness of mucoadhesive drug delivery. The precise $\mathrm{pH}$ and microenvironment at the polymer/membrane interface can significantly impact not only the strength of mucoadhesion but 
also the choice of mucoadhesive polymer (Smart, 2005; Yadav et al., 2010). Various disease states (e.g., common cold, gastric ulcer, etc.) can also alter the chemical and physical environment of the mucous membrane (Mythri et al., 2011; Tangri, 2011). Prolonged contact with the mucous membrane has also been reported to cause irritation (Tangri, 2011). Ultimately, mucous membrane turnover will eventually impact all mucoadhesive drug formulations (Yadav et al., 2010; Tangri, 2011); however, use of second generation mucoadhesive polymers that target, contact, and/or penetrate underlying cells may enhance the longevity of the adhesive and prove more effective platforms for mucoadhesive drug delivery (Lehr, 2000).

\section{CONCLUSION}

Mucoadhesion is a promising strategy for targeted, controlled drug delivery. Regardless of the specific molecular mechanism, it may prove more effective than other controlled delivery strategies based on (1) the intimate contact provided by the adhesive with an absorpative membrane, (2) the enhanced retention at the site of action, (3) the potential protection of sensitive biological

\section{REFERENCES}

Accili, D., Menghi, G., Bonacucina, G., Martino, P. D., and Palmieri, G. F. (2004). Mucoadhesion dependence of pharmaceutical polymers on mucosa characteristics. Eur. J. Pharm. Sci. Off. J. Eur. Fed. Pharm. Sci. 22, 225-234. doi: 10.1016/j.ejps.2003.12.011

Ahn, J., Choi, H., Lee, K., Nahm, J., and Cho, C. (2001). Novel mucoadhesive polymer prepared by template polymerization of acrylic acid in the presence of silk sericin. J. Appl. Polym. Sci. 80, 274-280. doi: 10.1002/10974628(20010411)80:2<274::AID-APP1096>3.0.CO;2-G

Amarpuri, G., Chaurasia, V., Jain, D., Blackledge, T. A., and Dhinojwala, A. (2015). Ubiquitous distribution of salts and proteins in spider glue enhances spider silk adhesion. Sci. Rep. 5:9030. doi: 10.1038/srep09030

Andersson, M., Holm, L., Ridderstråle, Y., Johansson, J., and Rising, A. (2013). Morphology and composition of the spider major ampullate gland and dragline silk. Biomacromolecules 14, 2945-2952. doi: 10.1021/bm400898t

Andrews, G. P., Laverty, T. P., and Jones, D. S. (2009). Mucoadhesive polymeric platforms for controlled drug delivery. Eur. J. Pharm. Biopharm. 71, 505-518. doi: 10.1016/j.ejpb.2008.09.028

Ashton, N. N., Roe, D. R., Weiss, R. B., Cheatham, T. E., and Stewart, R. J. (2013). Self-tensioning aquatic caddisfly silk: $\mathrm{Ca}^{2+}$-dependent structure, strength, and load cycle hysteresis. Biomacromolecules 14, 3668-3681. doi: $10.1021 / \mathrm{bm} 401036 \mathrm{z}$

Baeyens, V., Felt-Baeyens, O., Rougier, S., Pheulpin, S., Boisramé, B., and Gurny, R. (2002). Clinical evaluation of bioadhesive ophthalmic drug inserts (BODI) for the treatment of external ocular infections in dogs. J. Control. Release Off. J. Control. Release Soc. 85, 163-168. doi: 10.1016/S0168-3659(02) 00284-5

Barbi, M. D. S., Carvalho, F. C., Kiill, C. P., Barud, H. D. S., Santagneli, S. H., Ribeiro, S. J. L., et al. (2015). Preparation and characterization of chitosan nanoparticles for zidovudine nasal delivery. J. Nanosci. Nanotechnol. 15, 865-874. doi: 10.1166/jnn.2015.9180

Batchelor, H. (2005). Bioadhesive dosage forms for esophageal drug delivery. Pharm. Res. 22, 175-181. doi: 10.1007/s11095-004-1183-5

Bernkop-Schnürch, A., and Freudl, J. (1999). Comparative in vitro study of different chitosan-complexing agent conjugates. Pharmazie 54, 369-371.

Bernkop-Schnürch, A., Hornof, M., and Guggi, D. (2004a). Thiolated chitosans. Eur. J. Pharm. Biopharm. Off. J. Arbeitsgemeinschaft Für Pharm. Verfahrenstechnik EV 57, 9-17. doi: 10.1016/S0939-6411(03)00147-4 molecules, and (4) the improved bioavailability. Considering the potential of this drug delivery strategy, development of additional natural mucoadhesive polymers is paramount. Chief among these are spider aggregate and piriform silk, silkworm fibroin and sericin, and caddisfly silk. Based on their recognized biocompatibility (Ngwuluka et al., 2014), utilizing bioinspired silk polymers (i.e., aggregate silk, piriform silk, silkworm fibroin, sericin, and caddisfly silk) may mitigate the immune response while proving effective for controlled drug delivery.

\section{AUTHOR CONTRIBUTIONS}

$\mathrm{AB}$ is accountable for all work presented in this manuscript, including concept, research, drafting, revision, and final approval.

\section{FUNDING}

This work was funded by start up funds from North Dakota State University.

Bernkop-Schnürch, A., Krauland, A. H., Leitner, V. M., and Palmberger T. (2004b). Thiomers: potential excipients for non-invasive peptide delivery systems. Eur. J. Pharm. Biopharm. Off. J. Arbeitsgemeinschaft Für Pharm. Verfahrenstechnik EV 58, 253-263. doi:10.1016/j.ejpb.2004. 03.032

Blasingame, E., Tuton-Blasingame, T., Larkin, L., Falick, A. M., Zhao, L., Fong, J., et al. (2009). Pyriform spidroin 1, a novel member of the silk gene family that anchors dragline silk fibers in attachment discs of the black widow spider, Latrodectus hesperus. J. Biol. Chem. 284, 29097-29108. doi: 10.1074/jbc.M109.021378

Bré, L. P., Zheng, Y., Pêgo, A. P., and Wang, W. (2013). Taking tissue adhesives to the future: from traditional synthetic to new biomimetic approaches. Biomater Sci 1, 239-253. doi: 10.1039/C2BM00121G

Bravo-Osuna, I., Vauthier, C., Farabollini, A., Palmieri, G. F., and Ponchel, G. (2007). Mucoadhesion mechanism of chitosan and thiolated chitosanpoly(isobutyl cyanoacrylate) core-shell nanoparticles. Biomaterials 28, 2233-2243. doi: 10.1016/j.biomaterials.2007.01.005

Breslauer, D. N., Lee, L. P., and Muller, S. J. (2009). Simulation of flow in the silk gland. Biomacromolecules 10, 49-57. doi: 10.1021/bm800752x

Carvalho, F. C., Bruschi, M. L., Evangelista, R. C., and Gremiao, M. P. D. (2010). Mucoadhesive drug delivery systems. Braz. J. Pharm. Sci. 46, 1-17. doi: 10.1590/S1984-82502010000100002

Catron, N. D., Lee, H., and Messersmith, P. B. (2006). Enhancement of poly(ethylene glycol) mucoadsorption by biomimetic end group functionalization. Biointerphases 1, 134. doi: 10.1116/1.2422894

Ceulemans, J., Vinckier, I., and Ludwig, A. (2002). The use of xanthan gum in an ophthalmic liquid dosage form: rheological characterization of the interaction with mucin. J. Pharm. Sci. 91, 1117-1127. doi: 10.1002/jps.10106

Cevher, E., Sensoy, D., Taha, M. A. M., and Araman, A. (2008a). Effect of thiolated polymers to textural and mucoadhesive properties of vaginal gel formulations prepared with polycarbophil and chitosan. AAPS Pharm. Sci. Tech. 9, 953-965. doi: 10.1208/s12249-008-9132-y

Cevher, E., Taha, M. A. M., Orlu, M., and Araman, A. (2008b). Evaluation of mechanical and mucoadhesive properties of clomiphene citrate gel formulations containing carbomers and their thiolated derivatives. Drug Deliv. 15, 57-67. doi: 10.1080/10717540701829234

Choresh, O., Bayarmagnai, B., and Lewis, R. V. (2009). Spider web glue: two proteins expressed from opposite strands of the same DNA sequence. Biomacromolecules 10, 2852-2856. doi: 10.1021/bm900681w 
Clark, M. A., Hirst, B. H., and Jepson, M. A. (2000). Lectin-mediated mucosal delivery of drugs and microparticles. Adv. Drug Deliv. Rev. 43, 207-223. doi: 10.1016/S0169-409X(00)00070-3

Das Neves, J., Bahia, M. F., Amiji, M. M., and Sarmento, B. (2011). Mucoadhesive nanomedicines: characterization and modulation of mucoadhesion at the nanoscale. Expert Opin. Drug Deliv. 8, 1085-1104. doi: $10.1517 / 17425247.2011 .586334$

Davidovich-Pinhas, M., and Bianco-Peled, H. (2010). Mucoadhesion: a review of characterization techniques. Expert Opin. Drug Deliv. 7, 259-271. doi: $10.1517 / 17425240903473134$

De, S. (2003). Polymer relationships during preparation of chitosan-alginate and poly-l-lysine-alginate nanospheres. J. Controlled Release 89, 101-112. doi: 10.1016/S0168-3659(03)00098-1

Dong, Y., Dong, P., Huang, D., Mei, L., Xia, Y., Wang, Z., et al. (2015). Fabrication and characterization of silk fibroin-coated liposomes for ocular drug delivery. Eur. J. Pharm. Biopharm. 91, 82-90. doi: 10.1016/j.ejpb.2015.01.018

Donnelly, R. F., and Woolfson, A. D. (2015). "Bioadhesive systems for drug delivery," in Bioadhesion and Biomimetics: From Nature to Applications, eds H. Bianco-Peled and M. Davidovich-Pinhas (Boca Raton, FL: CRC Press), 235-260.

Fini, A., Bergamante, V., and Ceschel, G. C. (2011). Mucoadhesive gels designed for the controlled release of chlorhexidine in the oral cavity. Pharmaceutics 3, 665-679. doi: 10.3390/pharmaceutics3040665

George, M., and Abraham, T. E. (2006). Polyionic hydrocolloids for the intestinal delivery of protein drugs: alginate and chitosan-a review. J. Control. Release Off. J. Control. Release Soc. 114, 1-14. doi: 10.1016/j.jconrel.2006.04.017

Geurts, P., Zhao, L., Hsia, Y., Gnesa, E., Tang, S., Jeffery, F., et al. (2010). Synthetic spider silk fibers spun from Pyriform Spidroin 2, a glue silk protein discovered in orb-weaving spider attachment discs. Biomacromolecules 11, 3495-3503. doi: 10.1021/bm101002w

Gomes, S., Gallego-Llamas, J., Leonor, I. B., Mano, J. F., Reis, R. L., and Kaplan, D. L. (2012). Biological responses to spider silk-antibiotic fusion protein. J. Tissue Eng. Regen. Med. 6, 356-368. doi: 10.1002/term.437

Grabovac, V., Guggi, D., and Bernkopschnurch, A. (2005). Comparison of the mucoadhesive properties of various polymers. Adv. Drug Deliv. Rev. 57, 1713-1723. doi: 10.1016/j.addr.2005.07.006

Grawe, I., Wolff, J. O., and Gorb, S. N. (2014). Composition and substratedependent strength of the silken attachment discs in spiders. J. R. Soc. Interface R. Soc. 11:0477. doi: 10.1098/rsif.2014.0477

Haas, J., and Lehr, C.-M. (2002). Developments in the area of bioadhesive drug delivery systems. Expert Opin. Biol. Ther. 2, 287-298. doi: 10.1517/14712598.2.3.287

Hofmann, S., Wong Po Foo, C. T., Rossetti, F., Textor, M., Vunjak-Novakovic, G., Kaplan, D. L., et al. (2006). Silk fibroin as an organic polymer for controlled drug delivery. J. Controlled Release 111, 219-227. doi: 10.1016/j.jconrel.2005.12.009

Hua, S., Marks, E., Schneider, J. J., and Keely, S. (2015). Advances in oral nanodelivery systems for colon targeted drug delivery in inflammatory bowel disease: selective targeting to diseased versus healthy tissue. Nanomedicine Nanotechnol. Biol. Med. 11, 1117-1132. doi: 10.1016/j.nano.2015.02.018

Jiang, P., Liu, H., Wang, C., Wu, L., Huang, J., and Guo, C. (2006). Tensile behavior and morphology of differently degummed silkworm (Bombyx mori) cocoon silk fibres. Mater. Lett. 60, 919-925. doi: 10.1016/j.matlet.2005.10.056

Jones, J. A., Harris, T. I., Tucker, C. L., Berg, K. R., Christy, S. Y., Day, B. A., et al. (2015). More than just fibers: an aqueous method for the production of innovative recombinant spider silk protein materials. Biomacromolecules 16, 1418-1425. doi: 10.1021/acs.biomac.5b00226

Kalu, V., Odeniyi, M., and Jaiyeoba, K. (2007). Matrix properties of a new plant gum in controlled drug delivery. Arch. Pharm. Res. 30, 884-889. doi: 10.1007/BF02978841

Kean, T., and Thanou, M. (2010). Biodegradation, biodistribution and toxicity of chitosan. Adv. Drug Deliv. Rev. 62, 3-11. doi: 10.1016/j.addr.2009.09.004

Khandai, M., Chakraborty, S., Sharma, A., Pattnaik, S., Patra, C. N., Dinda, S. C., et al. (2010). Preparation and evaluation of algino-sericin mucoadhesive microspheres: An approach for sustained drug delivery. J. Adv. Pharm. Res. 1, 48-60.

Khutoryanskiy, V. V. (2011). Advances in mucoadhesion and mucoadhesive polymers. Macromol. Biosci. 11, 748-764. doi: 10.1002/mabi.201000388
Kim, K., Kim, K., Ryu, J. H., and Lee, H. (2015). Chitosan-catechol: a polymer with long-lasting mucoadhesive properties. Biomaterials 52, 161-170. doi: 10.1016/j.biomaterials.2015.02.010

Kundu, J., Patra, C., and Kundu, S. C. (2008a). Design, fabrication and characterization of silk fibroin-HPMC-PEG blended films as vehicle for transmucosal delivery. Mater. Sci. Eng. C 28, 1376-1380. doi: 10.1016/j.msec.2008.03.004

Kundu, S. C., Dash, B. C., Dash, R., and Kaplan, D. L. (2008b). Natural protective glue protein, sericin bioengineered by silkworms: potential for biomedical and biotechnological applications. Prog. Polym. Sci. 33, 998-1012. doi: 10.1016/j.progpolymsci.2008.08.002

Lammel, A. S., Hu, X., Park, S. H., Kaplan, D. L., and Scheibel, T. R. (2010). Controlling silk fibroin particle features for drug delivery. Biomaterials 31, 4583-4591. doi: 10.1016/j.biomaterials.2010.02.024

Lane, D. D., Kaur, S., Weerasakare, G. M., and Stewart, R. J. (2015). Toughened hydrogels inspired by aquatic caddisworm silk. Soft Matter 11, 6981-6990. doi: 10.1039/C5SM01297J

Lee, B. P., Dalsin, J. L., and Messersmith, P. B. (2002). Synthesis and Gelation of DOPA-Modified Poly(ethylene glycol) Hydrogels. Biomacromolecules 3, 1038-1047. doi: 10.1021/bm025546n

Lee, H. (2010). Biomaterials: intelligent glue. Nature 465, 298-299. doi: $10.1038 / 465298 \mathrm{a}$

Lehr, C. M. (2000). Lectin-mediated drug delivery: the second generation of bioadhesives. J. Control. Release Off. J. Control. Release Soc. 65, 19-29. doi: 10.1016/S0168-3659(99)00228-X

Lehr, C.-M., Bouwstra, J. A., Schacht, E. H., and Junginger, H. E. (1992). In vitro evaluation of mucoadhesive properties of chitosan and some other natural polymers. Int. J. Pharm. 78, 43-48. doi: 10.1016/0378-5173(92)90353-4

Li, J., and Xu, Z. (2002). Physical characterization of a chitosan-based hydrogel delivery system. J. Pharm. Sci. 91, 1669-1677. doi: 10.1002/jps. 10157

Ludwig, A. (2005). The use of mucoadhesive polymers in ocular drug delivery. Adv. Drug Deliv. Rev. 57, 1595-1639. doi: 10.1016/j.addr.2005. 07.005

Marriott, C., and Gregory, N. (1990). "Mucus physiology and pathology," in Bioadhesive Drug Delivery Systems, eds V. Lanaerts and R. Gurny (Florida, IL: CRC Press), 1-24.

Mythri, G., Kavitha, K., Kumar, M., and Singh, J. (2011). Novel mucoadhesive polymers-a review. J. Appl. Pharm. Sci. 01, 37-42.

Nagai, T., Yuji, N., Naoki, N., Yoshiki, S., and Kunio, S. (1984). Powder dosage form of insulin for nasal administration. J. Controlled Release 1, 15-22. doi: 10.1016/0168-3659(84)90017-8

Ngwuluka, N., Ochekpe, N., and Aruoma, O. (2014). Naturapolyceutics: the science of utilizing natural polymers for drug delivery. Polymers 6, 1312-1332. doi: 10.3390/polym6051312

Ohkawa, K., Miura, Y., Nomura, T., Arai, R., Abe, K., Tsukada, M., et al. (2013). Long-range periodic sequence of the cement/silk protein of Stenopsyche marmorata: purification and biochemical characterisation. Biofouling 29, 357-367. doi: 10.1080/08927014.2013.774376

Opell, B. D., and Hendricks, M. L. (2009). The adhesive delivery system of viscous capture threads spun by orb-weaving spiders. J. Exp. Biol. 212, 3026-3034. doi: 10.1242/jeb.030064

Opell, B. D., Karinshak, S. E., and Sigler, M. A. (2013). Environmental response and adaptation of glycoprotein glue within the droplets of viscous prey capture threads from araneoid spider orb-webs. J. Exp. Biol. 216, 3023-3034. doi: 10.1242/jeb.084822

Perry, D. J., Bittencourt, D., Siltberg-Liberles, J., Rech, E. L., and Lewis, R. V. (2010). Piriform spider silk sequences reveal unique repetitive elements. Biomacromolecules 11, 3000-3006. doi: 10.1021/bm1007585

Rodrigues, S., Dionísio, M., López, C. R., and Grenha, A. (2012). Biocompatibility of chitosan carriers with application in drug delivery. J. Funct. Biomater. 3, 615-641. doi: 10.3390/jfb3030615

Sahni, V., Blackledge, T. A., and Dhinojwala, A. (2010). Viscoelastic solids explain spider web stickiness. Nat. Commun. 1, 1-4. doi: 10.1038/ncomms1019

Sahni, V., Blackledge, T. A., and Dhinojwala, A. (2011). A review on spider silk adhesion. J. Adhes. 87, 595-614. doi: 10.1080/00218464.2011.583588

Sahni, V., Miyoshi, T., Chen, K., Jain, D., Blamires, S. J., Blackledge, T. A., et al. (2014). Direct solvation of glycoproteins by salts in spider silk glues enhances 
adhesion and helps to explain the evolution of modern spider orb webs. Biomacromolecules 15, 1225-1232. doi: 10.1021/bm401800y

Salamat-Miller, N., Chittchang, M., and Johnston, T. (2005). The use of mucoadhesive polymers in buccal drug delivery. Adv. Drug Deliv. Rev. 57, 1666-1691. doi: 10.1016/j.addr.2005.07.003

Serban, M. A., Panilaitis, B., and Kaplan, D. L. (2011). Silk fibroin and polyethylene glycol-based biocompatible tissue adhesives. J. Biomed. Mater. Res. A 98A, 567-575. doi: 10.1002/jbm.a.33149

Seves, A., Romanò, M., Maifreni, T., Sora, S., and Ciferri, O. (1998). The microbial degradation of silk: a laboratory investigation. Int. Biodeterior. Biodegrad. 42, 203-211. doi: 10.1016/S0964-8305(98)00050-X

Shaikh, R., Raj Singh, T., Garland, M., Woolfson, Ad., and Donnelly, R. (2011). Mucoadhesive drug delivery systems. J. Pharm. Bioallied Sci. 3, 89. doi: 10.4103/0975-7406.76478

Smart, J. D. (2005). The basics and underlying mechanisms of mucoadhesion. $A d v$. Drug Deliv. Rev. 57, 1556-1568. doi: 10.1016/j.addr.2005.07.001

Stewart, R. J., Ransom, T. C., and Hlady, V. (2011). Natural underwater adhesives. J. Polym. Sci. Part B Polym. Phys. 49, 757-771. doi: 10.1002/polb.22256

Stewart, R. J., and Wang, C. S. (2010). Adaptation of caddisfly larval silks to aquatic habitats by phosphorylation of $\mathrm{H}$-fibroin serines. Biomacromolecules 11, 969-974. doi: 10.1021/bm901426d

Tangri, P. (2011). Mucoadhesive drug delivery: mechanism and methods of evaluation. Int. J. Pharma Bio Sci. 2, 458-467.

Teramoto, H., and Miyazawa, M. (2005). Molecular orientation behavior of silk sericin film as revealed by ATR infrared spectroscopy. Biomacromolecules 6, 2049-2057. doi: 10.1021/bm0500547

Thakur, V., and Thakur, M. (2015). Handbook of Polymers for Pharmaceutical Technologies, Structure and Chemistry. Hoboken, NJ: John Wiley \& Sons, Ltd.

Torres, F. G., Troncoso, O. P., and Cavalie, F. (2014). Physical characterization of the liquid adhesive from orb-weaving spiders. Mater. Sci. Eng. C 34, 341-344. doi: 10.1016/j.msec.2013.09.030

Valenta, C. (2005). The use of mucoadhesive polymers in vaginal delivery. Adv. Drug Deliv. Rev. 57, 1692-1712. doi: 10.1016/j.addr.2005. 07.004

Vasanthavada, K., Hu, X., Tuton-Blasingame, T., Hsia, Y., Sampath, S., Pacheco, R., et al. (2012). Spider glue proteins have distinct architectures compared with traditional spidroin family members. J. Biol. Chem. 287, 35986-35999. doi: 10.1074/jbc.M112.399816

Wang, Y. J., Sanai, K., and Nakagaki, M. (2009). A novel bioadhesive protein of silk filaments spun underwater by caddisfly larvae. Adv. Mater. Res. 79-82, 1631-1634. doi: 10.4028/www.scientific.net/AMR.79-82.1631
Wittaya-areekul, S., Kruenate, J., and Prahsarn, C. (2006). Preparation and in vitro evaluation of mucoadhesive properties of alginate/chitosan microparticles containing prednisolone. Int. J. Pharm. 312, 113-118. doi: 10.1016/j.ijpharm.2006.01.003

Woertz, C., Preis, M., Breitkreutz, J., and Kleinebudde, P. (2013). Assessment of test methods evaluating mucoadhesive polymers and dosage forms: an overview. Eur. J. Pharm. Biopharm. 85, 843-853. doi: 10.1016/j.ejpb.2013.06.023

Wolff, J. O., Grawe, I., Wirth, M., Karstedt, A., and Gorb, S. N. (2015). Spider's super-glue: thread anchors are composite adhesives with synergistic hierarchical organization. Soft Matter 11, 2394-2403. doi: 10.1039/C4SM 02130D

Woodley, J. (2001). Bioadhesion: new possibilities for drug administration? Clin. Pharmacokinet. 40, 77-84. doi: 10.2165/00003088-200140020-00001

Xu, J., Soliman, G. M., Barralet, J., and Cerruti, M. (2012). Mollusk glue inspired mucoadhesives for biomedical applications. Langmuir 28, 14010-14017. doi: 10.1021/la3025414

Yadav, V. K., Gupta, A. B., Kumar, R., Yadev, J. S., and Kumar, B. (2010). Mucoadhesive polymers: means of improving the mucoadhesion properties of drug delivery system. J. Chem. Pharm. Res. 2, 418-432.

Yu, T., Andrews, G. P., and Jones, D. S. (2014). "Mucoadhesion and characterization of mucoadhesive properties," in Mucosal Delivery of Biopharmaceuticals, eds J. das Neves and B. Sarmento (Boston, MA: Springer US), 35-58. Available at: http://link.springer.com/10.1007/978-1-4614-9524$6 \_2$ [Accessed August 4, 2015].

Yucel, T., Kojic, N., Leisk, G. G., Lo, T. J., and Kaplan, D. L. (2010). Non-equilibrium silk fibroin adhesives. J. Struct. Biol. 170, 406-412. doi: 10.1016/j.jsb.2009.12.012

Zhang, Y.Q. (2002). Applications of natural silk protein sericin in biomaterials. Biotechnol. Adv. 20, 91-100. doi: 10.1016/S0734-9750(02)00003-4

Conflict of Interest Statement: The author declares that the research was conducted in the absence of any commercial or financial relationships that could be construed as a potential conflict of interest.

Copyright (c) 2015 Brooks. This is an open-access article distributed under the terms of the Creative Commons Attribution License (CC BY). The use, distribution or reproduction in other forums is permitted, provided the original author(s) or licensor are credited and that the original publication in this journal is cited, in accordance with accepted academic practice. No use, distribution or reproduction is permitted which does not comply with these terms. 